\title{
The POLITICIZE dataset: an inventory of deliberative mini-publics (DMPs) in Europe
}

\section{Emilien Paulis ${ }^{1} \cdot$ Jean-Benoit Pilet ${ }^{1} \cdot$ Sophie Panel ${ }^{1} \cdot$ Davide Vittori $^{1}$. Caroline Close ${ }^{1}$}

Published online: 7 July 2020

(c) European Consortium for Political Research 2020

\begin{abstract}
This note introduces the POLITICIZE dataset which contains information on the characteristics of 105 Deliberative Mini-Publics (DMPs) that took place in Europe between 2000 and 2020. Based on coding of experts regarding cases of real-life deliberative experiments in 18 different European countries, the dataset describes the core features of DMPs in Europe. It comprises information on three crucial dimensions: their composition (who deliberates?), their format (how do they deliberate?) and their role (what do they deliberate about and what are their prerogatives?). Hence, the note presents the different variables included in the dataset and reports empirical variations across them, thereby presenting the main contribution of the POLITICIZE dataset: delivering the most systematic and comprehensive efforts of data collection on mini-publics in Europe.
\end{abstract}

Keywords Deliberation $\cdot$ Democratic innovation $\cdot$ Europe $\cdot$ Mini-publics

\section{The POLITICIZE project}

The goal of the POLITICIZE project ${ }^{1}$ is to study how European citizens are evaluating reforms that are shifting some traditional prerogatives of representative institutions to non-elected bodies. Three types of such non-elected bodies are being studied: (1) deliberative mini-publics composed of citizens by lot, (2) technocratic governments that are fully or partly composed of ministers that are independent

\footnotetext{
1 The POLITICIZE project is a project supervised by Jean-Benoit Pilet (Université libre de Bruxelles). It has received funding from the European Research Council (ERC) under the European Union's Horizon 2020 research and innovation programme (Grant Agreement No 772695).
}

Emilien Paulis

epaulis@ulb.ac.be

1 Centre d'Etude de La Vie Politique, Université Libre de Bruxelles, Avenue Jeanne, 44 - CP 124, 1050 Brussels, Belgium 
experts or technocrats rather than elected politicians, and (3) bodies of experts that are appointed by representative institutions to take part to policy-making.

In this research note, we focus on the first dimension of the project, i.e. the study of deliberative mini-publics (thereafter DMPs). The first task in that respect was to conduct an inventory of DMPs initiated across Europe by national and regional public authorities between 2000 and 2020. The inventory is now available in two formats. First, on the project website, an online inventory is available to the public and to stakeholders. ${ }^{2}$ It presents detailed information sheets on each case of DMP covered. Second, a consolidated dataset is at the scholarly community's disposal for research purpose and accessible with this article. This research note presents the latter, the POLITICIZE dataset. ${ }^{3}$ Every year, further release of the dataset will incorporate new cases of DMP.

\section{Studying deliberative mini-publics in Europe}

The POLITICIZE project studies deliberative mini-publics in a broader context of democratic disenchantment among the public across consolidated democracies (Rosanvallon 2006; Papadopoulos 2013; Thomassen 2016). Facing this challenge, in many countries, elected politicians have tried to address the low levels of public trust in representative politics by testing institutional reforms offering citizens new opportunities to participate. Democratic innovations, such as citizens' forums, participatory budgeting or mini-publics, have burgeoned under different forms across established democracies: (Bedock 2017; Morel and Qvortrup 2017; Smith 2009; Zittel and Fuchs 2007).

In the POLITICIZE dataset, we are interested in one specific type of instrument: deliberative mini-publics (hereafter DMPs). Although there are several definitions used in the academic literature for DMPs (see Ryan and Smith 2014), we propose to work with a definition of DMPs based upon two basic constitutive elements: (1) it has to be a deliberative process, meaning that participating citizens reach their conclusions or recommendations after receiving information and engaging in a careful and open discussion about the issue or issues before them, and (2) it should be a mini-public, meaning that its members are selected to constitute, as far as possible, a representative subset of the wider population (meaning that fully open citizens' forums are not DMPs).

Democratic innovations of this kind are not new. The first experiments started in the 1970s with citizens' juries and planning cells tested in a few countries (Germany, USA), and later in the 1980s, with consensus conferences (Grönlund et al. 2014). Assemblies gained a broader audience within academia in the mid-2000s when two Canadian provinces (British Columbia and Ontario) and the Netherlands organised citizens' assemblies on electoral reforms (Fournier et al. 2011). Another landmark

\footnotetext{
${ }^{2}$ Politicize Project Website (2020). https://politicize.eu/inventory-dmps/.

${ }^{3}$ Paulis et al. (2020), POLITICIZE dataset, https://doi.org/10.7910/DVN/Z7X6GT, Harvard Dataverse, V1.
} 
was the Irish Constitutional Convention installed in 2012 (Suiter et al. 2016). Since then, many other bodies composed at least partly of citizens selected by lot emerged (Reuchamps and Suiter, 2016).

Yet, there is no systematic attempt to map and inventory the variety of organised DMPs. Comparative data that reflect the rich diversity of deliberative mini-publics is lacking and prevent scholars from reaching overarching conclusions about them and their role. The POLITICIZE dataset proposes to overcome this problem for Europe since 2000.

\section{Presentation of the dataset}

One of the main goals of the POLITICIZE project was to conduct the largest data collection so far on DMPs in Europe. In order to do so, it directly relies on efforts of national experts (scholars), active in 31 European countries and who have agreed to contribute to this collective effort. Their selection depended on their research interests and publications in the field of deliberative mini-publics, or more largely on their knowledge of their home country politics.

The unit of analysis in the database is a deliberative mini-public (DMP). Country experts had first to answer a short questionnaire about the existence of deliberative process in their home country at national or regional level since the beginning of the 2000s. As second step, they had to fill a standard form designed to elicit a certain number of exhaustive information about each of the relevant cases of DMP identified in their country. To be relevant, the cases had to comply with the following criteria:

1 The DMP has to take place between 2000 and 2020,

2 Public authorities (government, parliament, president) must be the organisers of the DMP. The formal involvement of public authorities may be very important or more limited (endorsing the initiative, commanding it, ...), but public authorities should be in charge of formally integrating the output of the mini-public into the policy-making process. We therefore exclude private, research-based or citizensbased initiatives such as G1000 in Belgium, We The Citizens in Ireland, The Citizens Assembly on Brexit in the UK, Der Bürgerrat Demokratie in Germany, or Demoscan in Switzerland,

3 Either national or regional levels' public authorities must be the organisers of the DMP. While the consolidated dataset focuses only on these two levels, a few mini-publics organised at local level and that were especially relevant due to their political impact are proposed additionally in the online inventory. Nonetheless, our goal was not to be comprehensive at that level. The coverage of local DMPs would imply too many cases with most often too little information available.

4 There is a formal political role in the policy-making process attributed to the DMP. The role could be to make recommendations to public authorities, to provide information on public opinion, to evaluate existing policies or institutions, up to (co)decision. 
Hence, after a careful review and assembling process, the POLITICIZE research team built up an inventory of 105 DMPs in dataset format. Its content is also available online, allowing POLITICIZE website visitors to navigate through the inventory of DMPs by sorting the cases according to certain of their features. The online inventory proposes also to the research community to contribute directly to the collective effort by pointing out missing cases and providing new entries. Before inclusion in the online inventory, the POLITICIZE team will screen these new additions.

For each case of DMPs, the dataset covers four dimensions (identifiers, composition, format and role) and their related information. We present them hereafter. Each variable corresponds to a column in the dataset file.

\section{DMP Identifiers}

The first, preliminary section of the dataset provides information that identifies and contextualises the DMP in terms of geographical and temporal scope.

Country This variable refers to the country where the DMP is held. So far, the dataset identifies 105 DMPs in 18 different European countries. Initially, the country scope was larger (31 countries: EU 27, UK, Norway, Iceland and Switzerland). However, we found out through our experts' preliminary questionnaires that, for many EU countries, no DMPs existed at national or regional levels (see further "Level" variable). Eastern and central EU countries particularly stood out from Western Europe on that aspect by having almost no deliberative experience at all, with the sole exception of Estonia (one case) and Romania (one case). In contrast, France, the UK and Austria are the three countries with the most cases that the dataset covered, with more than 15 DMPs inventoried since 2000 for each of them (Fig. 1).

Original name This variable contains the name of the DMP in original language.

Name This variable offers a translation of the name of the DMP in English.

Level This variable describes which public authorities' level is responsible for launching the mini-public. The POLITICIZE dataset focuses only on national or regional level mini-publics (Fig. 2).

Starting year/date These two variables provide the year and date when the first meeting of the mini-public took place. There seems to be a slight increase in the use of deliberative tools by public institutions over time (Fig. 3).

End year/date These two variables inform of the year and date of the DMP's last meeting (similar to the starting date for one-day event). Empty cells in the dataset refer to a few cases where the mini-public is established as a permanent body (e.g. German-speaking community of Belgium or the City Observatory of Madrid Region).

Summary This text variable provides a short descriptive summary of the case.

\section{DMP composition: who deliberates?}

The POLITICIZE dataset covers a first core feature of DMPs. It lies in their composition, answering thereby to the "who" question. As their name suggests, DMPs are 


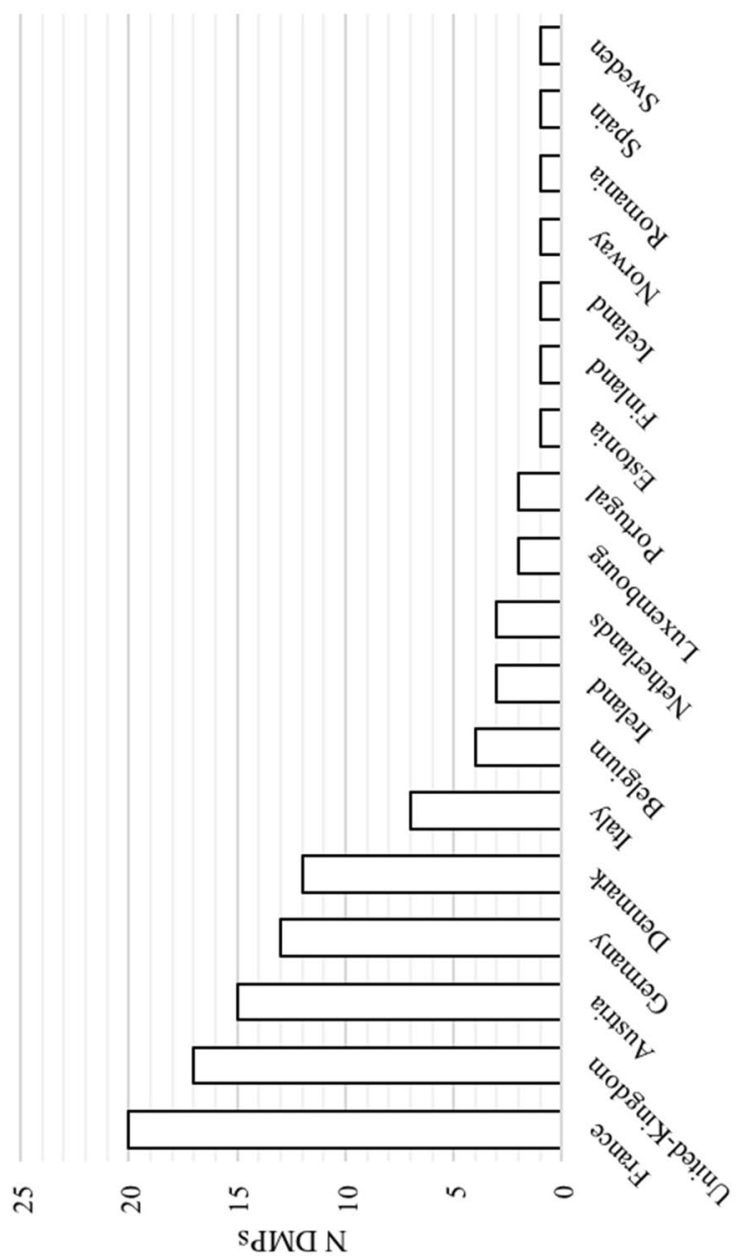



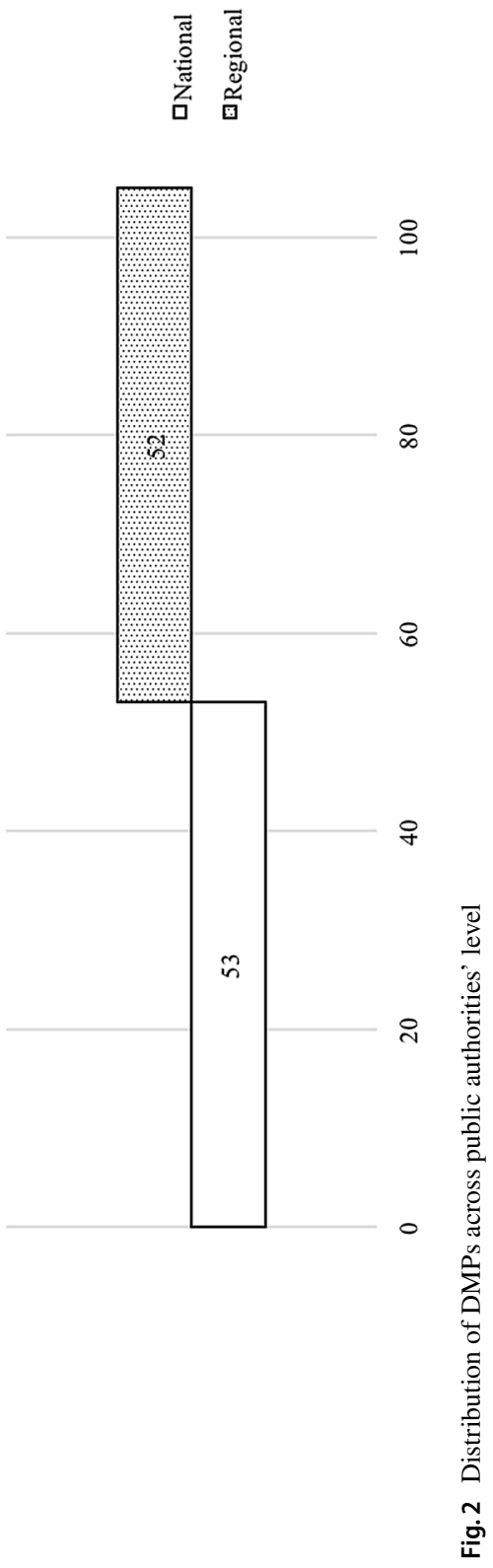

站 


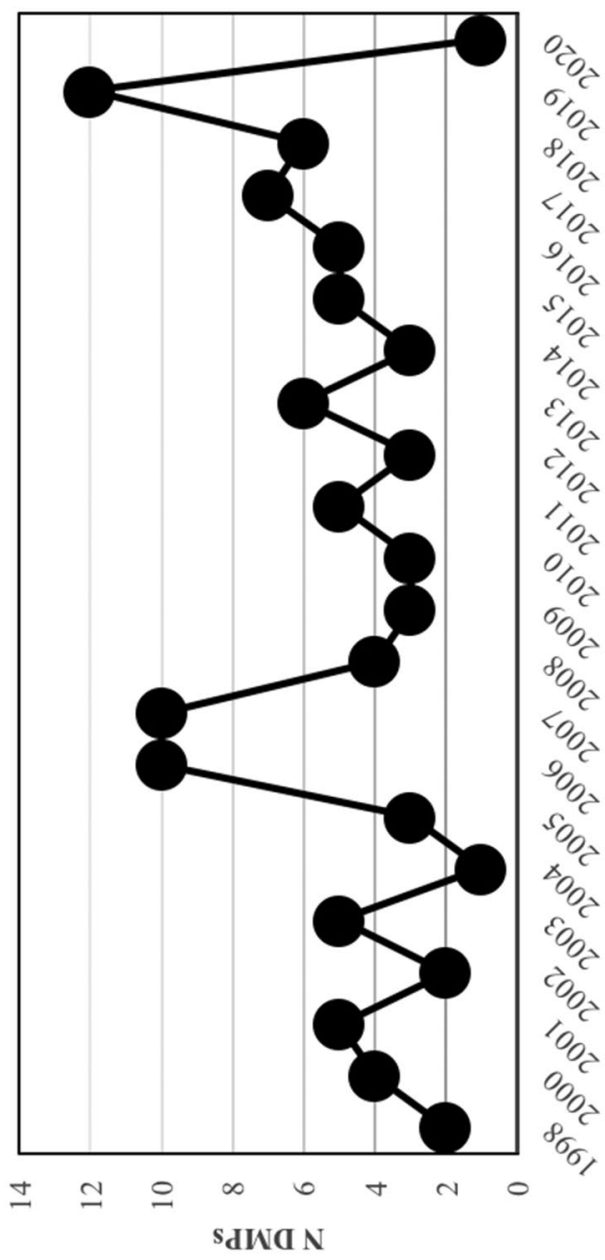

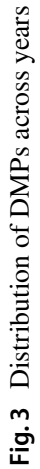


"mini-publics". This implies that they should gather people that are representative of the broader (maxi) public. Yet, beyond that simple definition, the question remains as who composes these DMPs in reality. The POLITICIZE dataset offers the possibility to examine this issue on the basis of past deliberative experiences, and so via three variables.

Type of DMP First, the dataset provides information on whether citizens only, or also other actors compose the DMP. By default, a "normal" mini-public involves only citizens in the deliberative process. It fits with the essential idea that DMPs' purpose is to give to citizens the opportunity to contribute directly to policy-making. If other types of actors already integrated into policy-making such as elected politicians but also other stakeholders (e.g. representatives of interest groups, NGOs or other organisations) participate directly in the deliberation, we considered such DMPs as "hybrid". Yet, the hybrid composition is not the most frequent and remains quite rare (10 out of the 105 cases covered by the dataset). These include a few examples in Ireland, the UK or in France. More recently, in Belgium, the regional parliament of Brussels has decided to create a new parliamentary committee composed of 45 citizens and 15 elected members of the parliament.

Number of citizens selected The second variable of interest regarding the composition of DMPs is the number of participants. The smallest mini-publics in the dataset gather around 10 participants. The largest ones reach several hundred participants. It is the case of the Icelandic National Assembly, which was set up in 2010 in the aftermath of the financial and economic crisis, gathered 950 citizens. Figure 4 reports the number of participants across the 105 cases of DMPs organised at national and regional levels in Europe between 2000 and 2020. We see that no dominant pattern emerges. There are about a third of mini-publics with 20 participants or less (32.2 per cent). Around 27.8 per cent gather from 20 to 50 participants, while 17.4 per cent are between 50 and 100 participants. Finally, 2 DMPs out of ten have more than 100 participants (22.2 per cent for the last two categories).

Selection method Regarding the composition of DMPs, the POLITICIZE dataset takes a third element into consideration: the selection method, i.e. how citizens are recruited. Our definition of DMPs postulates that "its members constitute, as far as possible, a representative subset of the wider population". Often, this idea of having a mini-public mirroring the maxi-public relates to the idea of selecting people by lot. The goal is to provide each citizen with an equal opportunity to participate. In order to do so, we may observe that in a few cases (about 20 per cent), authorities organising the DMP applied pure random selection. They extracted purely randomly a sample of the population from population registries. And selected citizens are invited to join. Yet, often, self-selection bias led to having mini-publics that are not real mirrors of the maxi-public. Some groups are systematically under-represented (younger and older citizens, lower educated, women, ethnic minorities, citizens residing far away from the DMP venue, and so on).

In order to compensate for that, in a vast majority of DMPs (75 per cent), organises applied representation criteria correcting for the underrepresentation of certain social groups. Some country experts explained in their case descriptions (available on the website) that the implementation of these representation criteria vary quite a lot across DMPs. In some cases, the technique is stratified random sampling. 


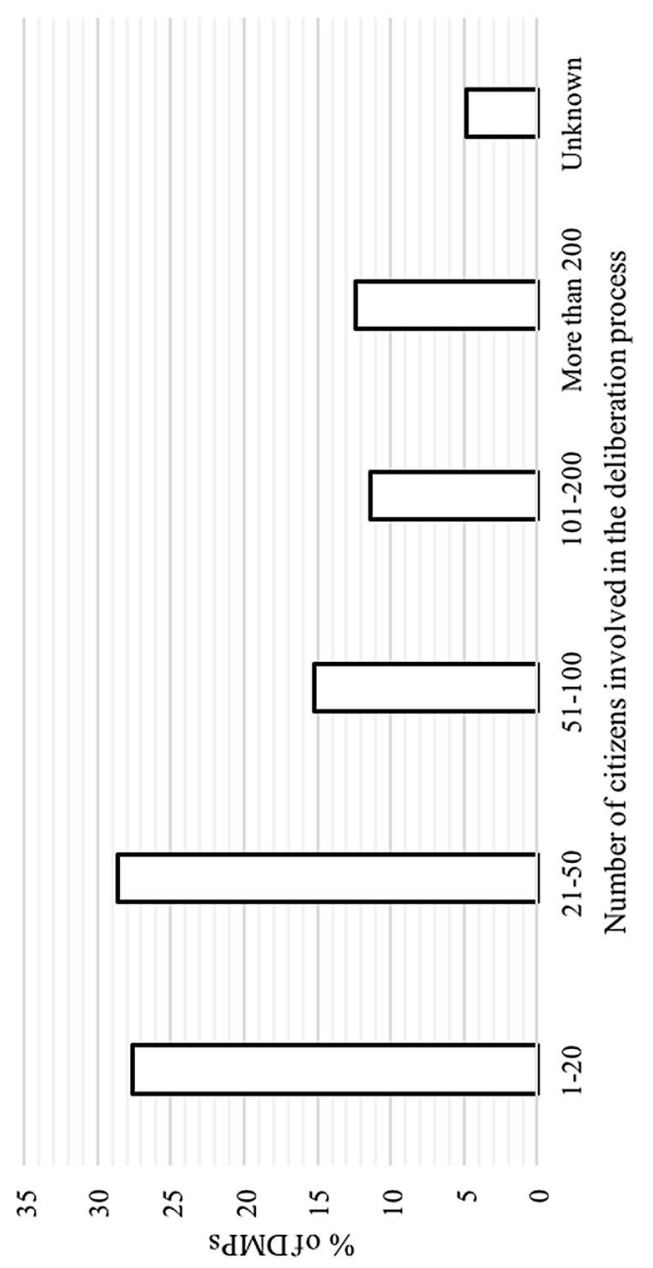




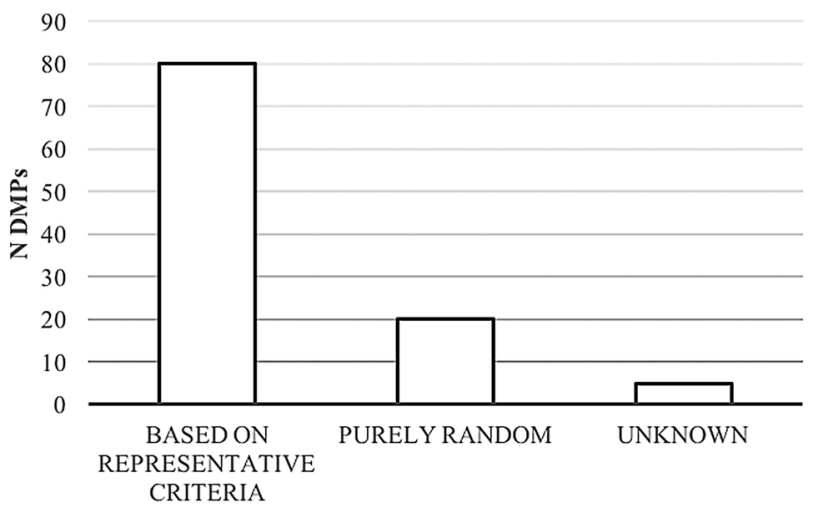

Fig. 5 Distributions of DMPs across selection methods

In others, there are quotas for some under-represented categories of the population. What also varied is the implementation of these representation criteria. In some cases, organisers of the DMP start with open invitation and apply representation criteria to recruit in a second phase. In other instances, the selection process starts with selecting a representative sample of the population applying representation criteria, and then whoever replies positively can join. Yet, what is clear is that, in line with our definition above, we do not count as cases of DMP bodies open to any citizens who are willing to participate without any selection by organisers (Fig. 5).

Selection criteria Moreover, if DMPs' composition apply representative criteria, the POLITICIZE dataset provides information on the criteria that were used to balance the sample of participants. This allows for an examination of the global benchmarks for composing a mini-public mirroring the broader population. The most frequent ones are sociodemographic criteria such as age, gender, education, occupation, family composition, migration background, or place of residence. Yet, some recruitment processes added other criteria. First, in some cases, they take into consideration the political positions of citizens. For example, the composition of the Scottish Citizens Assembly took three political attitudes into account: attitudes towards Scottish independence, attitudes towards UK's membership in the EU, and voting preferences in the Scottish Parliament elections. The organisers used similar political attitudes to select participants for the Welsh Citizen Assembly, or for the Danish deliberative polls related to referendums on EU matters. In Finland, previous voting behaviours were also part of the selection criteria to compose the 2013 Citizens Jury on Finnish Democracy. Another example is the 2018 Citizens Assembly on Social Care in the UK. One of the selection criteria was participants' view as whether government should reduce, increase, or keep taxation at the same level ${ }^{4}$

\footnotetext{
4 Citizens' Assembly on Social Care. Recommendation for funding adult social care. (2018) Report available at https://publications.parliament.uk/pa/cm201719/cmselect/cmcomloc/citizens-assembly-repor t.pdf.
} 
What may also happen, although less frequently, is the inclusion of behavioural criteria in relation to the topic of deliberation. For example, the Brussels Regional Parliament organised a DMP in 2017, which invited to formulate recommendations related to mobility. In order to include pedestrians, car users, public transport users, and cyclists, the recruitment process took into account the participants' mobility behaviours. Similarly, in 2016, the recruitment of the participants to the French mini-public on health care and big data considered also their usage of online public service platforms. Given this empirical diversity, the dataset also displays detailed information on selection criteria provided by country experts (Fig. 6).

\section{DMP format of deliberation: how do they deliberate?}

The second core characteristic of the DMPs covered by the POLITICIZE dataset is the format of deliberation, thereby dealing with the "how" question. One significant aspect of a "mini-public" is that is has to be deliberative: participants discuss and exchange among them on a policy issue in order to produce recommendations or evaluations. All DMPs should therefore be deliberative events. They cannot be a gathering of citizens who would simply vote on specific issues or would make claims without engaging in proper and respectful discussion with other participants. The POLITICIZE dataset shows how such deliberation organises practically and to what extent it varies from one case to one another.

Type of interaction A first element is the organisation of the deliberation. In the vast majority of instances, the format is a single venue with all participants meeting physically and interacting face-to-face. Yet, there are also a few examples of DMPs for which the organisers have fed the process by decentralising the deliberation in several physical venues, with insights coming from preliminary moments of deliberation held in different places across the country or region. An example of such procedure has been the UK Climate Change Citizens Summit in 2007. First, there were six regional workshops between late March and early April 2007. The workshops gathered 28-29 people each from a range of urban and rural locations. The workshops took place in Bristol, Birmingham, London, Newcastle, Nottingham and Manchester. Then, in a second stage, a reconvened event (the Citizens' Summit) occurred in London on 12 May 2007.

Another sporadically used possibility is to hold an online consultation open to all citizens and to feed the on-site deliberation with insights submitted online. A good example is the People's Assembly Deliberation Day in Estonia in 2013. The Deliberation Day was the final step of a broader process of both online and offline public consultations. In January 2013, an online crowdsourcing website popped up. Public authorities invited every Estonian citizen to propose ideas for improving the situation in areas such as elections, public participation, political parties and their funding. Besides, the process included also a consultation of scholars and practitioners as well as an offline thematic workshop. The transmission of all this material to participants of the actual Deliberation Day allowed for an enrichment of their reflections. Interestingly, over recent months, with the COVID-19 crisis, some DMPs went fully online for a certain period of time. It was the case, 
8
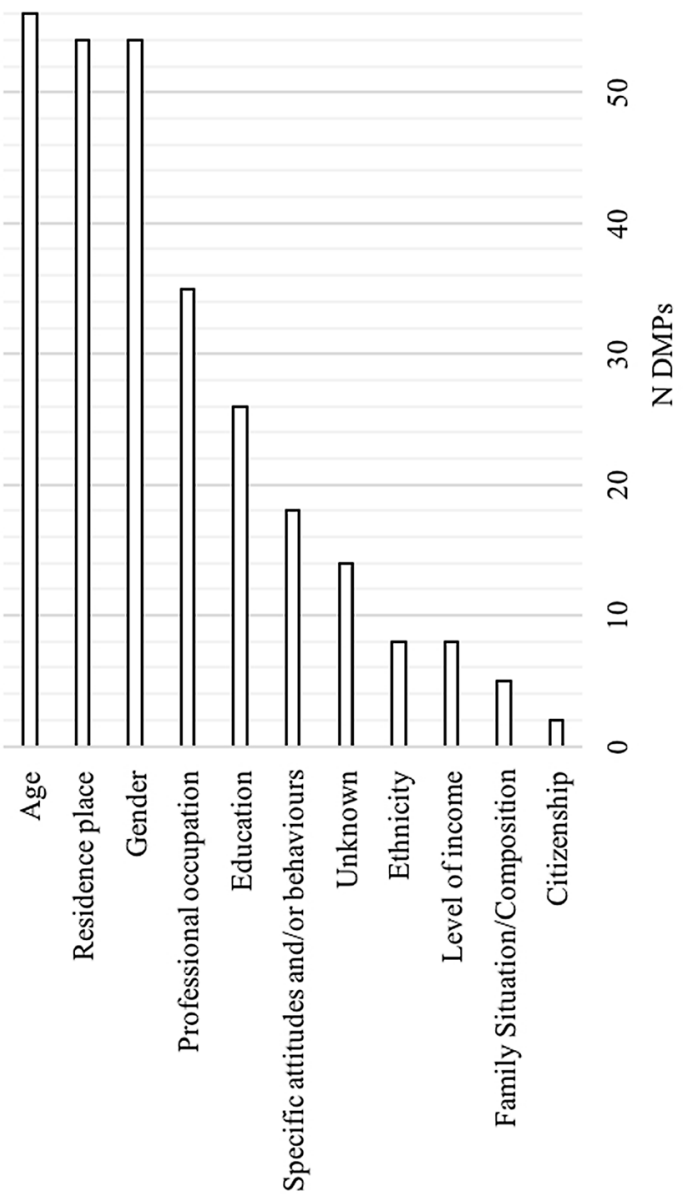

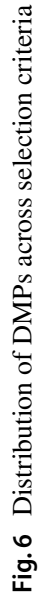

站 


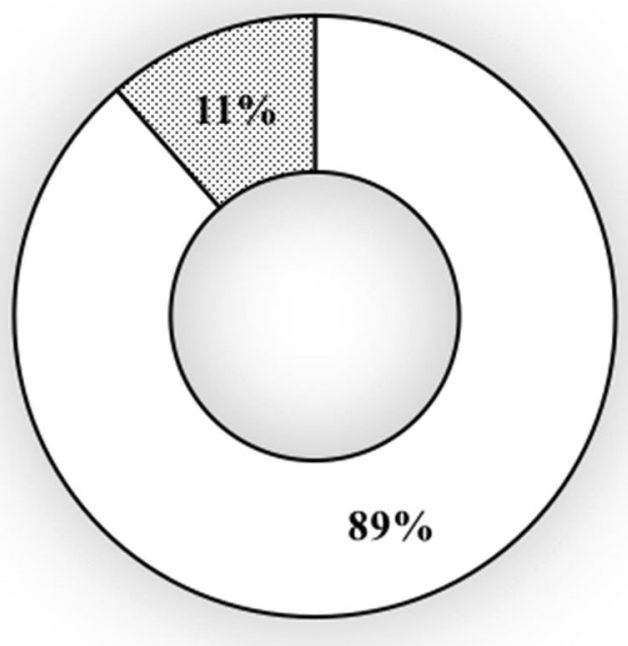

\section{QFace-to-face $\quad$ F Face-to-face and online}

Fig. 7 Distribution of DMPs across type of interaction

for example, of the UK Climate Citizens Assembly. It would be interesting to observe whether these recent developments lead to a wider use of online deliberation in DMPs (Fig. 7).

Duration The second dimension is the length of the debates. The trade-off is between longer events that make it harder to recruit citizens available to participate, and shorter mini-publics with easier recruitment but less time for a true deliberation and for richer outputs. This trade-off reflects in the dataset. The most frequent duration is to hold a DMP over one weekend (2-3 days-37.1 per cent). It was, for example, the format of the Austrian Citizens Conference on genetic data (2003), of most planning cells held in Germany for several decades, as well as of consensus conferences held repeatedly in Denmark and, to a lesser extent, in Norway.

A few DMPs are shorter, lasting only one day (22.9 per cent). And a few others last several weekends ( $4-5$ days $+6-10$ days' categories -24.8 per cent). The most frequent format appears to be DMPs lasting 2 or 3 days (i.e. a week-end and half a day). Finally, there are also a few interesting examples of DMPs that are presented as being 'permanent' although they are most often DMPs held over several weeks or months ( 4.8 per cent). It means that members are recruited for a period of several months with meetings being held regularly but with a varying agenda. One recent example is the Citizens Council set up in the German-Speaking Community of Belgium in 2019. There are a few other examples of DMPs sitting for several months (more than 10 days - 4.8 per cent). It was the case, for instance, for the Permanent committee for the funding of participatory projects in Rhône-Alpes Region in France (2006-9) (Fig. 8). 


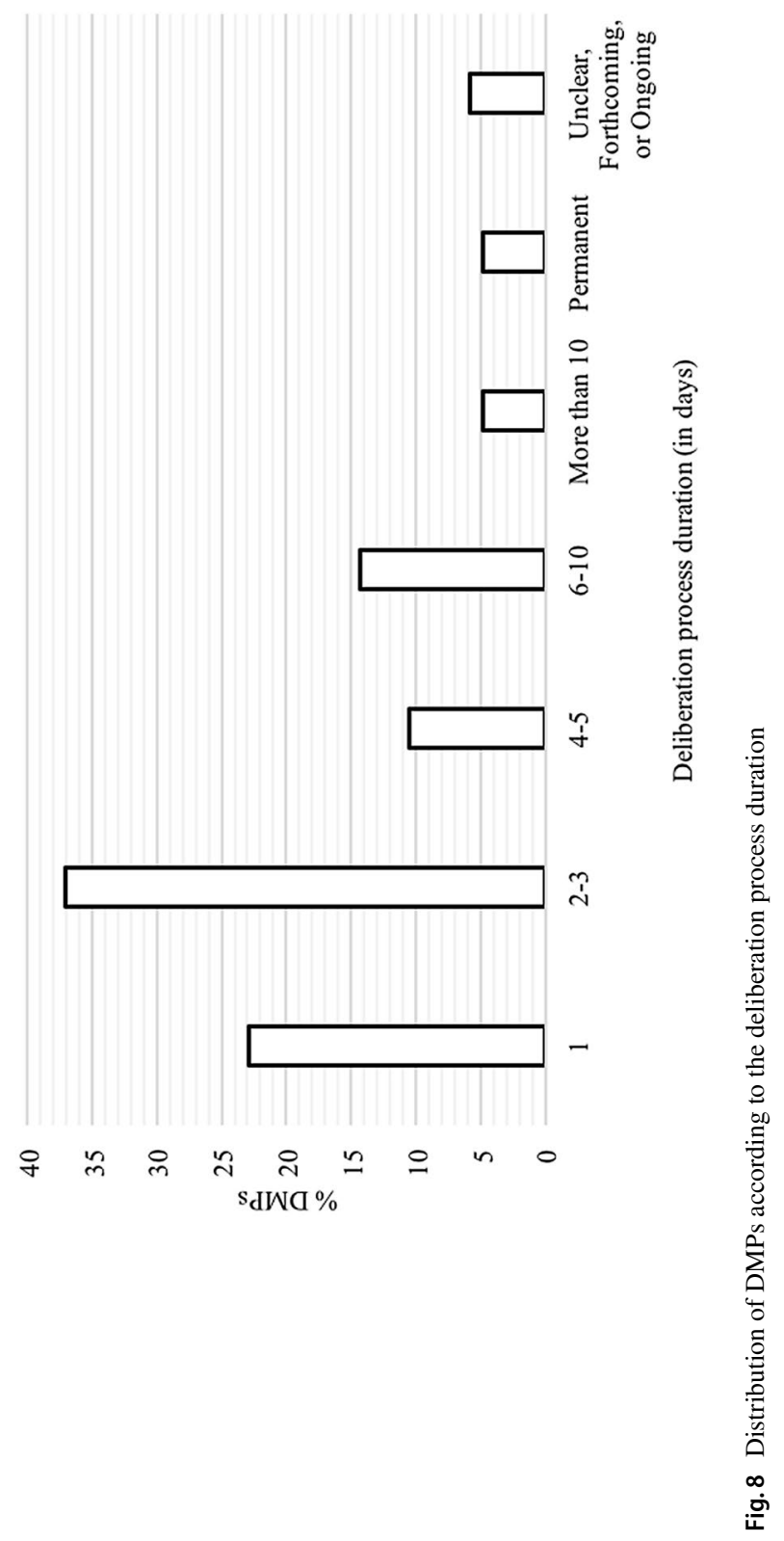

站 
Decision method The third dimension regarding the format of deliberation is how to (eventually) reach decisions. Most DMPs share a common goal: producing a report on what the participants have achieved together. And that output would then move to the organising public authorities. Often, it would also be accessible to the broader public and to the media. Yet, the decision of what to include into that final report does vary across DMPs. First, there is a distinction between DMPs that shall produce a written statement that formulates the outcome of deliberations-like in consensus conferences - and those that shall not produce such a joint statement but for which a report will describe the different opinions that participants exchanged and prompted-like in deliberative polls.

In the case of DMPs that shall produce a joint written statement, the question is then how to produce such an output, how to identify a limited set of recommendations or evaluations of the topic put in deliberation that participants approved for transmission to authorities. There is a need for a more formal way to filter all the propositions that may emerge from the deliberation. Two methods are frequent in that respect. The first is the consensus. Following the theoretical concept of consensus conferences, the idea is that through deliberation, participants will be able to reach a consensus on a few elements that they can all support. This method remains fairly common in DMPs as it accounts for about 42.8 per cent of all DMPs that the dataset inventoried ( $\mathrm{N}=45 \mathrm{DMPs})$. Yet, over the last decade, the same project shows that is has become more common to organise formal votes among participants at the end of the deliberative process and to retain recommendations or ideas that reached the widest majority ( $N=37$ DMPs). The goal remains to generate as much support as possible but reports sometimes explicitly state that all participants did not back some recommendations. The Irish Citizens Assembly in 2016, for example, held a series on final votes on the topics under deliberation and published the detailed results of these votes (Fig. 9).

\section{DMP role: what do they deliberative about and what are their prerogatives?}

The POLITICIZE dataset includes a third core characteristics of DMPs: their scope and prerogatives. The dataset proposes two main dimensions in this respect: what policy issues the DMPs deliberate about, and what is their actual political weight: are they just consultative bodies or can they be more than that?

Policy issues On the first aspect, there is a wide range of issues that public authorities attribute to DMPs. The most common topics are the environment and health. Yet, less than 25 per cent of mini-publics have debated these three topics. Many other topics have been the object of deliberation by DMPs. The consequences of scientific and technology developments have been, for example, a frequent topic of deliberation in Scandinavian countries and especially in Denmark with the Consensus conferences that the Danish Board of Technology organised until 2012. Political institutions have also been central for several mini-publics such as the Citizen Assembly on Electoral System in the Netherlands (2016), the Irish Constitutional Convention (2012-14), CONSTITULUX in Luxembourg (2012) or still during the National Citizen Forum "Diversity creates 


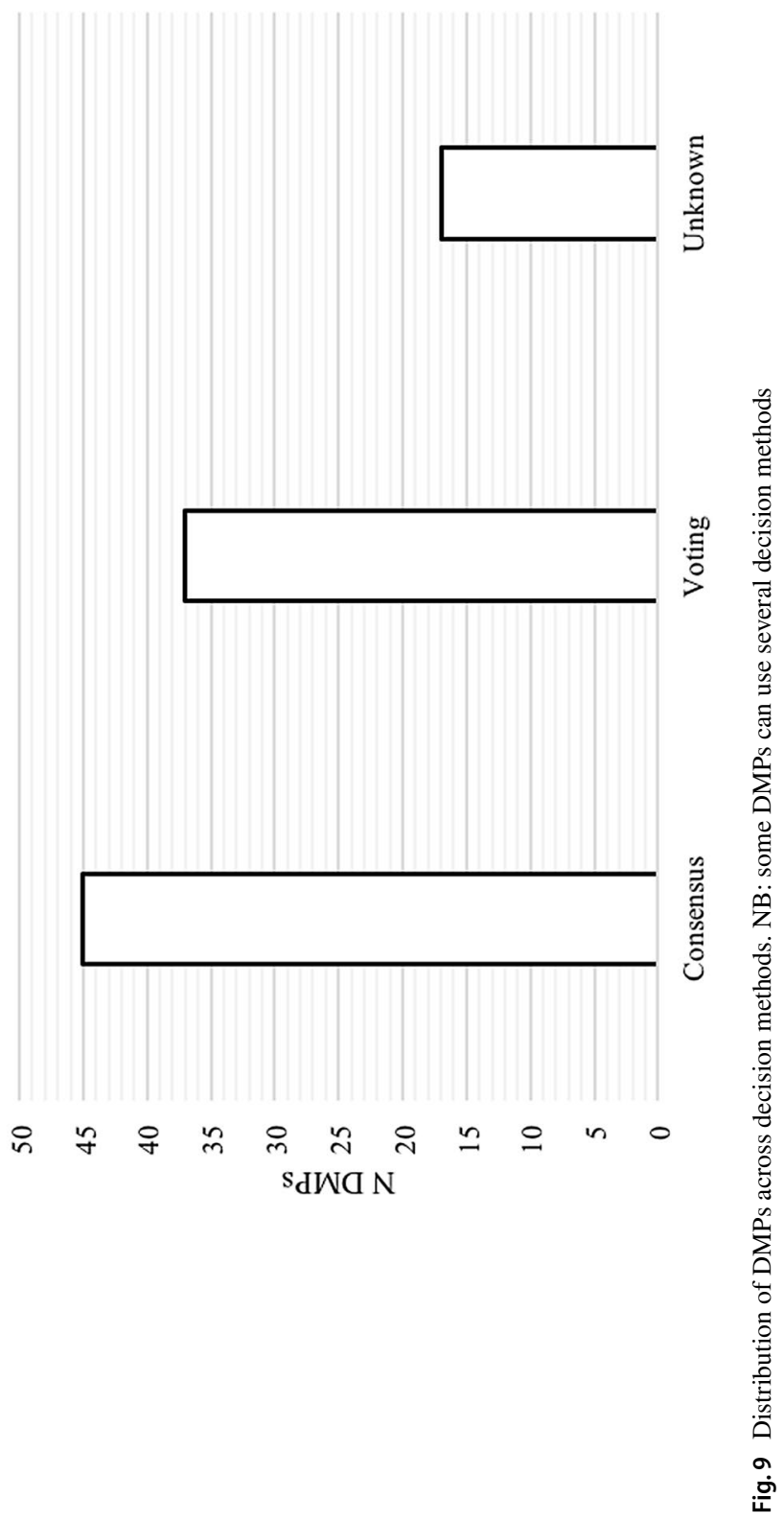

站。 
opportunities" in Germany (2011). But the variety of topics has gone beyond that with DMPs in charge of debating about planning, community development, education, aging, economic development, law and order, immigration and several other topics. The idea that DMPs could only suit for some specific issues, for example for issues that would not be too complex or too technical, does not hold when confronted to the reality of DMPs across Europe.

Two other elements are worth mentioning. First, public authorities set up a substantial number of DMPs with an open agenda (12.3 per cent). It was the task of the participants themselves to select the topics that they wanted to deliberate about. Second, it is not rare at all that a DMP deliberates on a variety of topics. It appears that about 60 per cent of all DMPs are attributed a single issue. It means that for the rest of DMPs (40 per cent), more than one issue was at the heart of the deliberation. Most often, these DMPs had to debate on 2 or 3 interrelated topics (Fig. 10).

In terms of what policy issues DMPs debated, a last element that is interesting to underline is that they seem to have evolved over the period that the POLITICIZE dataset covers (2000-2020). We can distinguish three main phases. At the start of the period (2000-2005), the most often debated policy issues were health and science-related development (especially in Denmark, France and Germany). In a second phase, around 2010, the environment became by far the most often deliberated issue. Issues related to planning (mobility, transport, urban planning) became also a frequent topic considered by DMPs. Finally, more recently (2015-2020) institutional issues emerged as a hot topic for several DMPs (in Ireland, Luxembourg, Estonia, Finland, Iceland, Scotland). DMPs with open agendas also became more frequent (Fig. 11).

Prerogatives Finally, and perhaps most importantly when it comes to the broader impact of DMPs on contemporary democracies, it is important to consider what actual political role has this form of democratic innovation. Do DMPs remain pure advisory bodies or do we observe some instances of DMPs that have a stronger role, perhaps going in the direction of mini-publics as second chamber of parliament as discussed, for example, by Gastil and Wright (2019)? Moreover, the literature has shown that the lack of clear and decisive prerogatives for DMPs is one of the reasons why many citizens refuse to participate in such forms of democratic innovation (Jacquet 2017).

Looking at the 105 cases of DMPs across Europe that the POLITICIZE project inventoried, this is not the way these bodies have functioned at the moment. In almost all instances, DMPs were mere advisory bodies. Their role was to evaluate existing policies to debate on policy issues, and to formulate recommendations to share with public authorities. But in all instances these authorities have no formal obligations to follow and accept recommendations from mini-publics (no decision power). Elected institutions remain sovereign. The sole exception is one hybrid DMP in France that the region Rhônes-Alpes permanently established from 2006 to 2009. Its main role was to allocate funding to participatory democracy projects on behalf of the Region. Finally, there are 3 cases of DMPs with both a prospective and retrospective advisory role. It is the case of a permanent citizen council that the German-speaking community in Belgium established in 
요

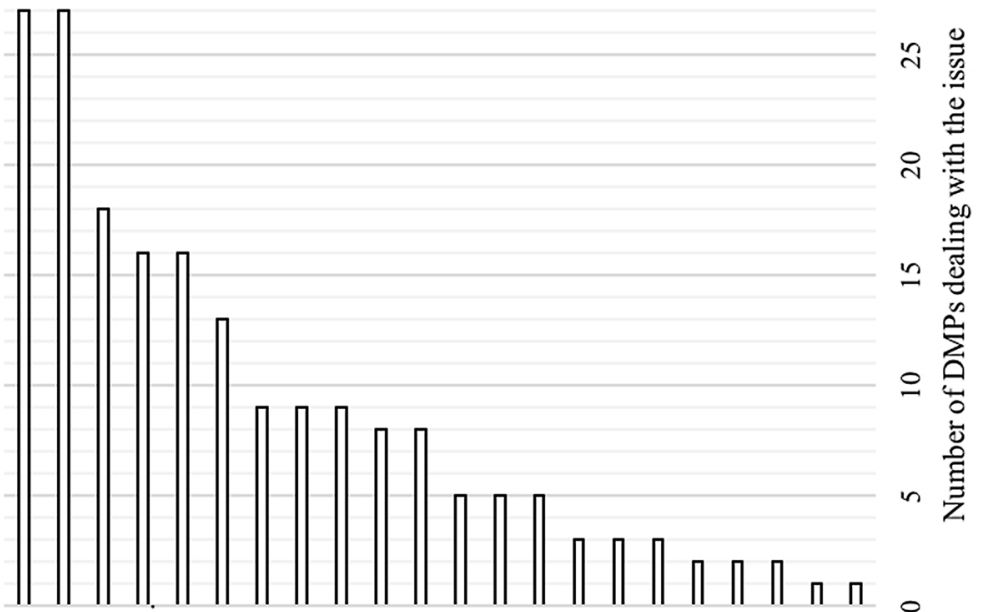

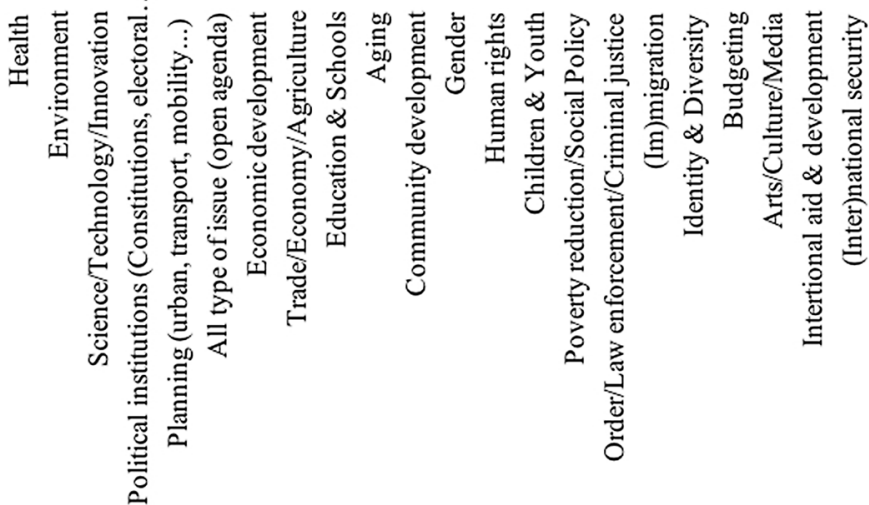

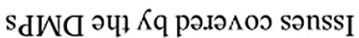



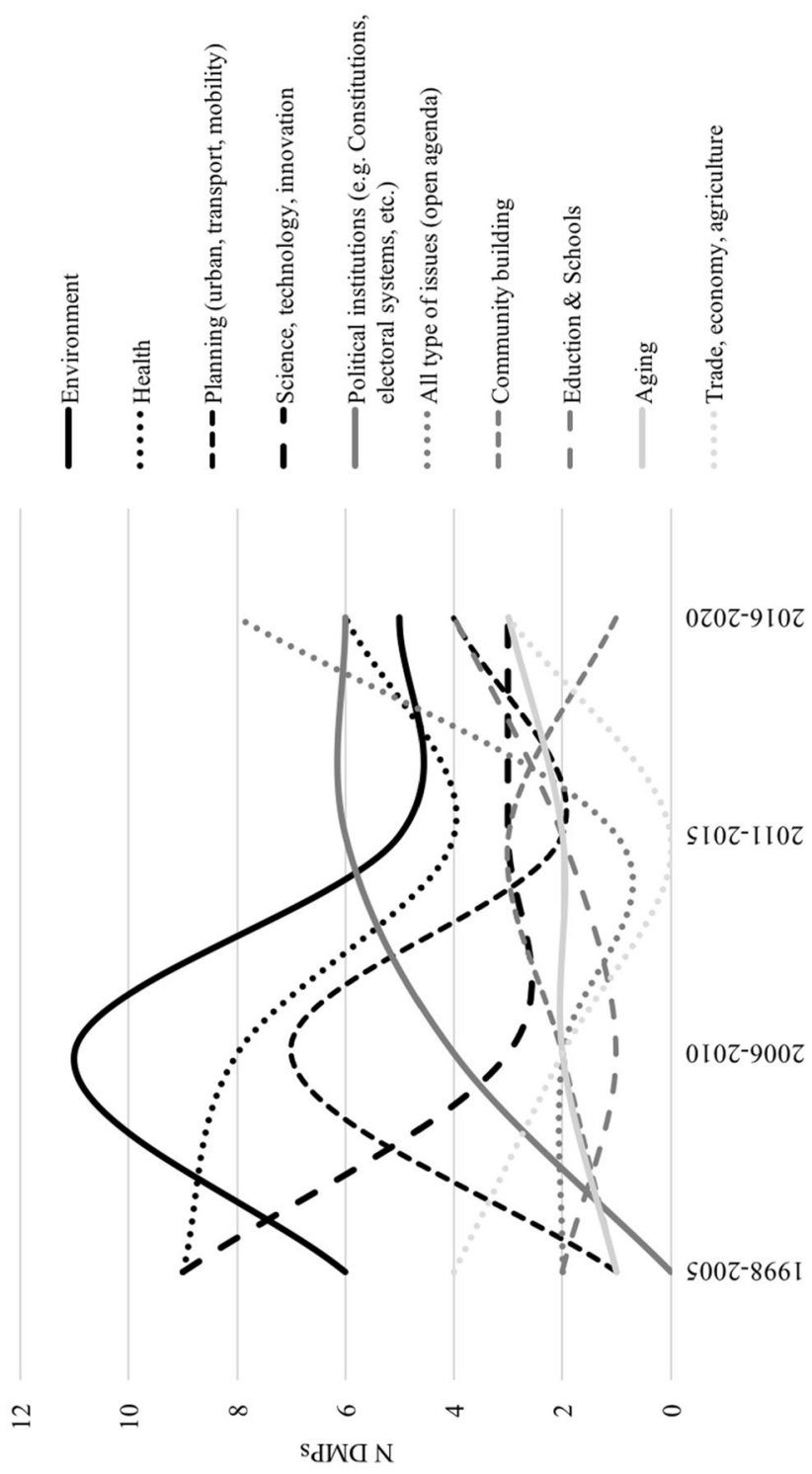

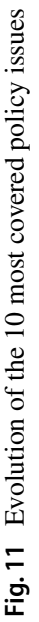




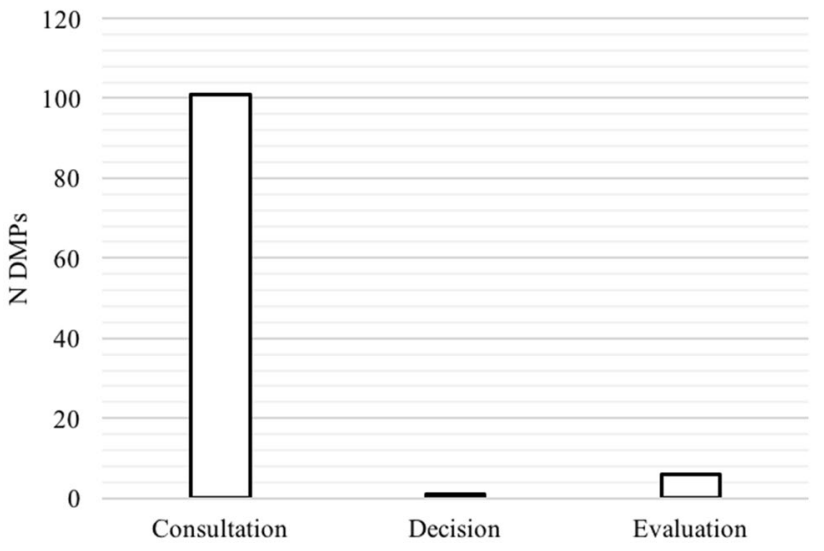

Fig. 12 Distribution of DMPs across prerogatives

2019, the citizen panels of the Swedish Region of Skane since 2014, and a French citizen jury that took place in Poitou-Charentes in 2009 (Fig. 12).

Outcomes and Links The POLITICIZE dataset provides also a descriptive text variable on how public authorities may have informally taken into consideration DMPs' output, as well as access to further sources (reports, useful links, etc.). In some cases, we may observe that representative institutions decided to give real weight to recommendations from mini-publics. In Ireland, after the Constitutional Convention, the pressure was strong on the government to put to referendums at least a few of the recommendations made by the mini-public. In the subsequent citizens' convention, the same kind of informal pressure also led the Irish government to put some recommendations of citizens to the popular vote. After the citizens' assemblies on the reform of the electoral system, the two Canadian provinces of British Columbia and Ontario used this combination of a mini-public plus referendum. Another logic that may apply is to systematically organise a debate in parliament on the report that the mini-public made. The hope is that it would facilitate the translation of citizens' recommendations into actual policy initiatives. The most advanced example is the Citizens Council of the GermanSpeaking Community of Belgium. The elected assembly of this federal entity of Belgium adopted a new procedure. It specifies that the Citizen Council must present the report to the elected assembly, but also that the relevant parliamentary committee must produce a report that will describe the implementation of the recommendations. In case the elected assembly would not implement some recommendations of the Citizen Council, it requires mandatory, explicit justifications. In addition, it implies the organisation of a joint meeting between the parliamentary committee and the citizens, and so to discuss this report with public authorities. Most public authorities do not go that far, but there is a growing trend towards more comprehensive reaction of representative institutions to the recommendations formulated by DMPs. 


\section{Main contribution}

The POLITICIZE dataset proposesthe most comprehensive and systematic data collection efforts about DMPs that national and regional public authorities organised across Europe since 2000. For the 105 cases that the first version of the dataset covered, ${ }^{5}$ it contributes to offer comparable information on three crucial dimensions: their composition, their format and their political role.

- In terms of composition, the dataset can help scholars to emphasize that DMPs may differ a lot in participants' recruitment and selection: in their number, in their profiles, or in the potential association of other actors than citizens. With regard to the format, the dataset shows that there may be significant variations in the format that the DMPs take, which can take place in multiple locations, for less or much more than a weekend, sometimes with an online platform enriching offline debates, and finally with quite some variations on how to produce and approve the final report.

- Regarding the political role, the dataset illustrates that there is a wide range of policy issues that DMPs discussed. DMPs can be either single or multiple issueoriented. On the other hand, the dataset calls for looking at the prerogatives of DMPs, which turn out to be up to now essentially advisory (consultation or evaluation) rather than genuinely decisional.

In short, all the elements that the POLITICIZE dataset covered makes it a substantial resource that puts the emphasis on the need for a more careful examination of what deliberative mini-publics are empirically and of what they mean theoretically, both for the scholars' interest in this form of democratic innovations and for political actors, practitioners and citizens that are the main stakeholders of mini-publics.

Acknowledgements The POLITICIZE Database is part of a research project financed by the European Research Council (ERC) under the European Union's Horizon 2020 research and innovation programme (Grant Agreement No 772695). We would like to thank all country experts who contributed to the data collection, as well as the team of the C03 Project 'Doing Mini-Publics' (https://www.sfb1265.de/en/subpr ojects/doing-mini-publics/) for sharing their data on mini-publics in Germany. The authors are also grateful for the comments they received from the reviewers.

\section{References}

Bedock, C. 2017. Reforming democracy. Institutional engineering in western Europe. Oxford: Oxford University Press.

Fournier, P., H. van der Kolk, K. Carty, A. Blais, and J. Rose. 2011. When citizens decide: Lessons from citizen assemblies on electoral reform. Oxford: Oxford University Press.

Gastil, J., and E.O. Wright. 2019. Legislature by Lot: Transformative Designs for Deliberative Governance. London: Verso Books.

\footnotetext{
${ }^{5}$ It remains an ongoing effort. Updates will come up.
} 
Grönlund, K., A. Bächtinger, and M. Setälä (eds.). 2014. Deliberative mini-publics: Involving citizens in the democratic process. Colchester: ECPR Press.

Jacquet, V. 2017. Explaining non-participation in deliberative mini-publics. European Journal of Political Research 56 (3): 640-659.

Morel, L., and M. Qvortrup. 2017. The Routledge handbook to referendums and direct democracy. London: Routledge.

Papadopoulos, Y. 2013. Democracy in crisis? Politics, governance and policy., London: Palgrave.

Reuchamps, M., and J. Suiter (eds.). 2016. Constitutional Deliberative Democracy in Europe. Colchester: ECPR Press.

Rosanvallon, P. 2006. La contre-démocratie. La politique à l'âge de la defiance. Paris: Seuil.

Ryan, M., and G. Smith. 2014. Defining Mini-Publics. In Deliberative mini-publics involving citizens in the democratic process, ed. K. Grönlund, A. Bächtiger, and M. Setala. Colchester: ECPR Press.

Smith, G. 2009. Democratic innovations. Designing institutions for citizens participation. Cambridge: Cambridge University Press.

Suiter, J., D. Farrell, and C. Harris. 2016. The Irish constitutional convention: A case of 'high legitimacy'? In Constitutional deliberative democracy in Europe, ed. M. Reuchamps, and J. Suiter, 33-54. Colchester: ECPR Press.

Thomassen, J. 2016. What's gone wrong with democracy, or with theories explaining why it has? In Citizenship and democracy in an era of crisis, ed. T. Poguntke, S. Robteutscher, R. Schmitt, and S. Zmerli, 34-52. London: Routledge.

Zittel, T., and D. Fuchs (eds.). 2007. Participatory democracy and political participation: Can participatory engineering bring citizens back in?. New York: Routledge.

Publisher's Note Springer Nature remains neutral with regard to jurisdictional claims in published maps and institutional affiliations.

Emilien Paulis is postdoc assistant (POLITICIZE, ERC project) at the Universite libre de Bruxelles (ULB). His research interests focus on citizen's political engagement at large, with a strong emphasis on the interpersonal, network dynamic of political attitudes and behaviours' formation.

Jean-Benoit Pilet is researcher and professor in political science at the Universite libre de Bruxelles (ULB). Interested in elections, political parties, and representative institutions, he has re-oriented his research towards citizens distrust towards representative democracy and demands of reforms that are associated with it. In this framework, he is the main coordinator of the POLITICIZE Project (www.politicize.eu), which benefits from an ERC grant and seeks to better untangle how European citizens evaluate the alternatives to representative democracy.

Sophie Panel is postdoc assistant (POLITICIZE, ERC Project) at the Université libre de Bruxelles (ULB). Her research interests include quantitative war studies, the comparative analysis of authoritarian regimes, and international political economy. She questions also conceptions of democracy and political representation.

Davide Vittori is postdoc assistant (POLITICIZE, ERC Project) at the Université libre de Bruxelles (ULB). His research deals with party systems and organizations in Southern Europe, voting behaviour and populism. He has also specialised in digital (party) politics as well as technocratic governments and ministers.

Caroline Close is researcher and professor in political science at the Université libre de Bruxelles (ULB). She studies political parties, elections, and dynamics of representation and participation at large. 